JELTL (Journal of English Language Teaching and Linguistics) e-ISSN: 2502-6062, p-ISSN: 2503-1848

2018, Vol. 3(3)

www.jeltl.org

\title{
The Frequency Effect on the Acquisition of -ING Form Structure by Indonesia L2 Learners
}

\author{
Muhammad Fahruddin Aziz \\ Magister Department of Yogyakarta State University, Indonesia \\ e-mail: azizfahruddin@gmail.com \\ Pratomo Widodo \\ Magister Department of Yogyakarta State University, Indonesia \\ e-mail:prat_wid@yahoo.com
}

\begin{abstract}
Even though-ing form is acquired earlier based on the natural order hypotheses of L2 morpheme acquisition (Krashen, 1981), it remains difficult for L2 learners to comprehend mainly for those who are rarely exposed to the targeted linguistic feature inputs. A number of investigations were already carried out to find out the frequency effect on the acquisition of verbs as a complement (gerund and infinitive), yet this paper was designed to identify the frequency effect on the acquisition of English -ing form structure by Indonesia L2 learners. Participants consisted of four groups from different semester (1,3,5, and 7). Each semester also indicated various language exposure experienced by L2 learners. Each group comprised 10 participants. Data were collected by employing the writing test to elicit-ing form production including interview and observation. The coding of students' composition and the scoring were used to interpret frequency effect on students' acquisition and their misconceptions in composing a sentence containing -ing forms. The findings revealed that the rate of frequent language exposure was not the only factor that contributes to the development of students' language proficiency. The rate of frequency inputs of -ing form structure accessed by learners fairly contributed to students' constructional schemas in accordance with the high score. Each word possessed various frequency inputs of distribution which then led them to any deviant production. In addition, intra-lingual errors were responsible for any misconception perceived by learners (incomplete application of rule, ignorance of rule restriction, and false concepts hypothesized).
\end{abstract}

Keywords: Usage-Based Theory, Constructional Schemas, Type and Token

Frequency, -ing Form Structures 


\section{INTRODUCTION}

Non-finite verbs (-ing form and infinitives) are the features of English structure which are dominantly exist in the constituent of a sentence. They can act for subject, verb, subject complement, object complement, adverb and the phrasal modification (Greenbaum \& Nelson, 2002). The characteristics of the two structures often mislead students' understanding. The distribution of the two structures takes place illogically. It confirms that verbs as -ing forms or infinitives are interconnected systematically. The particular structure sometimes can be the only right choice of the constituent. They can also take different properties that may influence another constituent. For example, in English, a predicate 'enjoy' generally takes -ing form complement, however another does not. In addition, the similar form and function sometimes can be lexically different that influence the properties of other constituents; 'his riding a bike is regarded somewhat dangerous' and 'quick writing is a complicated way' (Taher, 2015).

It is not that easy for learners to acquire the knowledge of non-finite verbs, since they turn out a subordinate construction that modifies another matrix constituent. The constituents of non-finite verb are hardly explained by language practitioners and grammarians (Kitikanan, 2011; Taher, 2015). It convinces that the construction is rather difficult to classify and clarify. Additionally, for-non English speakers, this construction messes up their conception. This matter eventually encourages the researchers to investigate the difficulty of classifying this construction underwent by ESL Learners.

Repetitive experiences of using particular linguistic features are regarded as a factor that contributes to strengthen cognitive capacity or conceptual linguistic realization (Baybee, 2010; Bybee \& Thompson, 1997). Thus, in accordance with its nature, frequency, typically so-called 'repetition', is a principal factor in SLA. According to (Ellis, 2002) the frequency of linguistic elements exposed to second language (L2) learners can be a principal facilitator in SLA.

The grammatical terms are often misinterpreted by Indonesia's ESL Learners so that the deviation production containing the two features was found in their writings which were syntactically ambiguous and caused the change of meaning. Gerund, Verbal noun, -ing deverbal noun, verbal adjective, -ing deverbal adjective and participle are grammatical terms that are lexically and inflectionally different (Quirk., et. al, 1985). In addition, infinitive (both bare and to infinitive) is another English grammatical term in which a word base of verb as the main structure. -ing form and infinitive constitute the knowledge of abstract linguistic pattern which is much regarded difficult to acquire and learn in the language instruction. The learners appeared to produce particular linguistic structure based on what was already learned or exposed to them. The following description illustrates the usage of non-finite verbs composed by students. A number of errors are found from their writings:

[1] I am very exciting.

[2] The airplane delay to taking the boarding time.

[3] I will taking a new phone tomorrow.

[4] Studying is my hobby.

[5] Rido is the headmaster whose boring. 
Errors were still found in learner's writings in using -ing form. Sentence (1) was syntactically ambiguous in which-ing form was not properly embedded. - ed form was more correctly put in the construction that explained the interest someone referred to. In the sentence (2), -ing form was embedded without additional particle to which was typically attached prior to infinitive construction. The particle to, on certain occasion, was regarded as a prepositional particle or infinitive marker. Particle to as the preposition was followed by -ing form construction. However, the case (2) was not the prepositional particle and the verb join was not normally put any preposition or infinitive.

The sentence (3) contained -ing form construction which was omitted, infinitive construction should be used as the constituent of modality. Therefore, the construction was created, for example, 'I will take a new phone tomorrow'. In the sentence (4), it is syntactically ambiguous as mode of interpretation (noun phrase) or mode of an action (clause) (Taher, 2015). It was probably meant that $<$ that i study certain subject is my hobby> or <certain lesson is my hobby>. Verbal noun was sometimes treated as a deverbal noun that referred to a concrete noun or abstract noun denoting personal reference, the result from an action, and the process or state of Taher (2015). In sentence (5), the construction fairly included -ing form, yet the use of subordinator (WH clause) was totally wrong given that the word "whose" indicated the possession of the personal reference. The subordinator 'who' was found correct in this case.

Previous investigation was already carried out by (Vecellotti \& De Jong, 2013) investigating the difficulties of L2 learners in producing the verbal complement structure in their direct oral speech. They investigated infinitival and-gerundival VCs produced by ESL high intermediate learners with various language backgrounds. They observed the construction in the production of VC structure and the necessity of matrix verb. The findings showed that learners created lots of VC constructions but not always accurately. The common errors in VC structure usage consisted of either using no marker or using both. Additional research by (Taher, 2015) studied problematic forms as to nominalization: gerund, verbal noun, and deverbal noun. These nominals are regarded problematic because of several reasons. The first reason is that they contain the distinct degree of combining nominal and verbal properties. Thus, the alternative of these nominals for particular structure is not easily predictable. The second one is that there are a number of inconsistencies regarding the use of terminologies. The inconsistent terminology is then confusing for the researcher, teachers, and even learners. (Keawchaum \& Pongpairoj, 2017) investigated the role of frequency that affect SLA which focused on the use of gerund and infinitive by L1 Thai Learners. Particular verbs and the use of verbal complements were selected based on high frequency of corpus data that confirmed a widely-used construction. The findings then proved that -ing form (gerund) was acquired later. The high frequency also contributed to low-level students' constructional schemas.

The researcher is much inspired to investigate the same case with Indonesia's L1 context. To deal with the gap, the researcher was interested in investigating whether the rate of frequency affected students' accuracy in composing-ing form 
structures, whether or not the rate of frequency influences students' preference or constructional schemas, and what misconceptions were perceived by learners in the acquisition of -ing form.

\section{LITERATURE REVIEW}

\subsection{The Usage-Based Theory}

This theory explains that language processing, language acquisition, language change, and the knowledge of language are derived from the actual usage of language and the contextual concept created through events of the language use (Tomasello, 2003; Croft \& Cruse, 2004; Baybee, 2010). This theory explains that factors which may contribute to the development of linguistic proficiency is determined by the actual use of language or the frequent language inputs exposed to an individual instead of relying on the innate capacity.

\subsubsection{Constructional Schema}

The experts also argue that the usage-based theory copes with the development of cognition capacity affecting the language use and the ability to construct language structure. Repetitive experiences of using the language can improve someone's cognition capacity or conceptual interpretation of particular linguistic structure (Schwartz \& Causarano, 2007). Constructional schemas are then acquired through the actual language use which is recognized, categorized, frequently repeated, memorized, conceptualized, and associated with the contextual meaning through the cognitive capacity (Dabrowska, 2004; Langacker, 2008). Therefore, the role of cognition is utilized to understand the linguistic structure and meaning.

\subsubsection{Types of Frequency}

Since the knowledge of linguistic is derived from the frequent language use instead of the natural feeling (innate capability), the language use can therefore influence a person's linguistic proficiency. A large number of linguistic feature inputs or the frequent language exposure 'repetition' which is so-called 'frequency' can encourage students to have ability of conceptualizing a language structure and associating with meaning through the cognitive capacity. Frequency is distinguished into two; both token frequency and type frequency (Baybee, 2010; Bybee \& Thompson, 1997; Croft \& Cruse, 2004).

Token frequency is the occurrences of a word or phrase found in the total possible distribution of a text, for instance, 'finding' or 'i am going to'. Meanwhile, type frequency is occurrences of the particular lexical items or syntactical markers which is distributed in a sentence (Baybee, 2010; Bybee \& Thompson, 1997; Croft $\&$ Cruse, 2004)

Thus, Frequency is distinguished into two sorts; low-frequency and highfrequency which indicate that a syntactical construction typically occurs frequently or more widely used than other constructions. (Keawchaum \& Pongpairoj, 2017) 


\subsection{English Linguistic Features}

\subsection{1 -ing Form Structure}

English suffixes comprise many categories including -ing affixes. The affix ing can be classified as derivation and inflection. The -ing affix is considered as a noun or an adjective to mark the change of meaning or category (derivation). The ing affix also takes a role, on the other hand, to mark grammatical function (inflection). The following are a list of -ing form categories:

Table 1. Suffix -ing

\begin{tabular}{ccc}
\hline Sorts & Suffixes & Category \\
\hline- ing $^{I}$ & Derivation & Noun \\
- ing $^{2}$ & Derivation & Adjective \\
- ing $^{3}$ & Inflection & Verb \\
\hline
\end{tabular}

This classification is likely to be neglected and over-generalized in the distribution of a sentence. This matter leads some learners to make errors. The further understanding on -ing form construction needs to be delivered by a teacher. It is found that some words are just added by -ing form itself. However, they are lexically classified into several categories.

The constituents of a sentence certainly depend on their forms and functions (Greenbaum \& Nelson, 2002). A word may contain a different lexical category (noun, adjective, or verb), for example, but may be a same function when grouped and ordered. -ing form as a suffix serves to carry grammatical information (inflection) or change the meaning or word classes (derivation) which is embedded to the initial word (base). The base sing as a lexical item of verb, For example, has a range of forms (singing as a noun), (singing as an adjective), and (singing as a verb).

There are particular terms to address the nominalised form from verbs (-ing form) by a number of linguists; gerund, -ing deverbal noun, and verbal noun (Taher, 2015). Nominal -ing form may refer to the actual performance, yet it is also neutral to any aspectual indication (Quirk., et. al, 1985). For example, 'he enjoys singing a song'. The -ing clause as non-finite clause can be classified as finite clause 'he enjoys that he sings a song'. The -ing clause is regarded as gerund which is lexically verb and inflectionally nominal 'nominal verb) (Quirk., et. al, 1985). However, Gerund is sometimes regarded the same as verbal noun by adding suffix -ing which acts for nominalization (Taher, 2015). However, another term -ing deverbal noun which adds suffix -ing is also hardly defined and sometimes misleads students' understanding.

1. Most verses of the psalm have multiple readings.

2. The killing of the president was an atrocious crime.

In order to distinguish both terms, it is important to know that gerund and -ing deverbal nouns include verbal nouns. It is so-called -ing deverbal noun while the construction can be pluralized. The word 'readings' is classified as -ing deverbal noun due to its pluralisation. The word 'readings' can replace the function of the concrete noun 'books, magazine, and so on'. Moreover, the word 'killing' is classified as verbal noun due to none of pluralisation and the replacement of concrete noun. Since the researcher will investigate the acquisition of verbal 
complement mainly acts for nominal form in the constituent of sentence, the researcher will not study a lot about the terms. According to (Quirk., et. al, 1985) ing form consists of some functions:

(1) Subject: watching television keeps them out of mischief.

(2) Subject complement: her first job had been selling computers.

(3) Direct object: he enjoys playing practical jokes.

(4) Prepositional complement: i am responsible for drawing up the budget.

(5) constituents of noun phrase as Modification

a. Noun Head: Brown's deft painting of his daughter is a delight to watch.

b. Pre modification: the swimming pool near the coastal area is more comfortable.

In addition, -ing form can also function as adjectival, adverbial, and predicative (Greenbaum \& Nelson, 2002). -ing form as adjectival is also called as verbal adjective, deverbal adjective, and meanwhile, -ing participle which modifies a noun head in the constituent of phrase or object complement (Quirk., et. al, 1985).

\subsection{Language Misconception}

Learning constitutes a collective practice. Students' may digest new piece of information which corresponds to their prior belief. Since students' having solid foundation, the new information interconnects more easily. Nonetheless, if the students do not prepare everything to deal with the pieces, they may get difficulties to realize a new fact (Maigoro., et. al, 2017). If the new fact encounters with prior information or tightly-retained ideas, the students may pay no attention to the new facts so that it corresponds with their previous concept or understanding.

If new concept corresponds with the prior understanding, meaningful learning would come about. Thus, it is essential to realize that the old realization students employ to the learning setting assist them build their own concepts (Maigoro., et. al, 2017). When instructors explain particular ideas in a range of subject matters, they are giving explanation to students with their pre-instructional awareness in relation to the theme. Nonetheless, Students' previous awareness can be erroneous, irrational or misinformed. These erroneous comprehensions are so called as alternative conceptions or misconceptions, (or intuitive theories) (Maigoro., et. al, 2017).

\subsubsection{The Theory of Error Analysis (EA)}

In the language analysis mainly analysing students' deviant language production, Error Analysis (EA) is generally employed to investigate learners' linguistic competence in producing the target language. It is first-investigated by Corder in1970s along with other colleagues. It accounts for explanation and analysis of errors in learner's interlanguage system proposed by (Brown, 1994). The term interlanguages familiarized by (Selinker, 1972) that denotes to systematic awareness that holds on learners' L1 and L2. Therefore, the researcher attempts to investigate misconception of students' composing nominal -ing form construction based on the approach of error analysis (hereafter EA). 
Deviation in language production is subdivided into three; error, mistake and lapse. Error is related to learner's linguistic competence in producing the language; which occurs due to lack of knowledge towards target language. Mistake is related to learner's linguistic performance and lapse is a situation which occurs because a learner is less concentrated, nervous, forgotten, and so on. (Norrish, 1983)

Error of competence is classified into two kinds: 1) interlingual error; two languages have distinct linguistic system, it will enable to produce so-called interference (negative transfer), 2) intralingual error and developmental error; it corresponds with students' second language comprehension (how to understand norm of rule) and it is also caused by the significant differences among languages which cause any complexity of internal structure itself. (Richards, 1974)

Intralingual and developmental errors are also classified into the following categories; overgeneralization which is an incorrect structure produced by learners in constructing the target language (e.g. "he may goes to the market" where English enables "he may go" and "he goes"), ignorance of rule restriction which is caused by the failure of realizing the restriction of the particular rule which is not correctly used in a different context (e.g. "i admit to love her" where English enables "i try to tell you"), incomplete application of rules which is caused by deficient construction of trial developed by learners (e.g. "The guy, is standing at the building entrance, donates an orphanage funds" where English also enables "the baby is crying because an object is dropped on his head"), and false-concept hypothesized which has something to do with learners' faulty comprehension of distinction in the target language rule (e.g. "i am boring" where English also enables "the film is boring to see”) (Richards, 1974).

\section{RESEARCH METHODS}

\subsection{Population and Sample}

The total participants consisted of 100 students which were categorized based on their semester; the first semester, the third semester, the fifth semester, and the seventh semester of the academic year in the English department. The participants involved in each semester were subdivided into 10 as the sample of the research. The purposive sampling was chosen based on subsequent requirements; they had the identical background in the department of education and teacher training, different levels of language proficiency (that indicated any experience of particular linguistic feature exposure), and last but not least the familiar surrounding situation for the researcher.

\subsection{Instrument}

\subsubsection{The production of research instrument}

The researcher organized and managed the instrument of the research utilized to provide the required data. Essay writing test used to diagnose any erroneous production of -ing form structures and to consider any tendency of -ing form constructions frequently composed by L2 learners. The writing test comprised a range of verbs used as the main constituents of -ing form "studying", "building", 
"painting", "interesting", and "trying". The frequency of -ing form verbs and the distribution were counted based on the rate of occurrence in the BNC corpus.

Each -ing form verb was selected based on the searching of corpus data to obtain the occurrence of possible -ing form constructions. 200 random quests of -ing form were calculated to see the frequency rate of occurrences. Phrasal idioms were not considered in the calculation of frequency since they probably represents a range of meanings able to affect the comprehension of student's answering the test. In addition, incomplete constituents of a sentence were not also incorporated. All of the selected -ing form structure frequencies are illustrated in the subsequent table.

The student was respectively given one of 5 different matrix verbs "studying", "building", "painting", "interesting", and "trying". Students were then asked to construct 4 words (building, painting, trying, and studying) respectively into four different sentences. Meanwhile, the word (interesting) was directed to be two possible constructions. The number of constructions directed depended on the normal rules of -ing form structure constituent. The directions of the writing test are described as follow:

1. Make four different sentences using the word "studying"

2. Make four different sentences using the word "building"

3. Make four different sentences using the word "painting"

4. Make four different sentences using the word "trying"

5. Make two different sentences using the word "interesting"

To get more comprehensive explanation, the researcher attempted to group the rate of frequency in a table. The description of BNC corpus frequency was illustrated in the following table:

Table 2: frequency of -ing form construction

\begin{tabular}{|c|c|c|c|c|}
\hline Word & $\begin{array}{l}\text { (Type F) } \\
\text {-ing form }\end{array}$ & $\begin{array}{c}\text { Function/distr } \\
\text { ibution }\end{array}$ & $\begin{array}{c}\text { Terms of linguistic feature } \\
\text { Usage }\end{array}$ & Occurrences \\
\hline Study & Studying & \multirow{5}{*}{ Nominal } & \multirow{5}{*}{$\begin{array}{ll}\text { 1. } & \text { Verbal noun } \\
\text { 2. } & \text {-ing deverbal noun } \\
\text { 3. } & \text { Gerund }\end{array}$} & $69 / 200$ \\
\hline Build & Building & & & $116 / 200$ \\
\hline Paint & Painting & & & $141 / 200$ \\
\hline Interest & Interesting & & & $0 / 200$ \\
\hline Try & Trying & & & $52 / 200$ \\
\hline Study & Studying & \multirow{5}{*}{ Adverbial } & \multirow{5}{*}{ 4. -ing Participle } & $9 / 200$ \\
\hline Build & Building & & & $2 / 200$ \\
\hline Paint & Painting & & & $2 / 200$ \\
\hline Interest & Interesting & & & $1 / 200$ \\
\hline Try & Trying & & & $15 / 200$ \\
\hline Study & Studying & \multirow{5}{*}{ Predicative } & \multirow{5}{*}{ 4. -ing Participle } & $80 / 200$ \\
\hline Build & Building & & & $7 / 200$ \\
\hline Paint & Painting & & & $6 / 200$ \\
\hline Interest & Interesting & & & $0 / 200$ \\
\hline Try & Trying & & & $93 / 200$ \\
\hline Study & Studying & Adjectival & 5. $\quad$ Verbal adjective & $24 / 200$ \\
\hline
\end{tabular}




\begin{tabular}{|c|c|c|c|c|}
\hline & & \multirow{5}{*}{\multicolumn{2}{|c|}{$\begin{array}{ll}\text { 6. } & \text {-ing Deverbal adjective } \\
\text { 7. } & \text {-ing Participle } \\
\text { 8. } & \text { Verbal noun } \\
\text { 9. } & \text {-ing deverbal noun }\end{array}$}} & \\
\hline Build & Building & & & $4 / 200$ \\
\hline Paint & Painting & & & $34 / 200$ \\
\hline Interest & Interesting & & & $198 / 200$ \\
\hline Try & Trying & & & $25 / 200$ \\
\hline
\end{tabular}

\subsubsection{Scoring criteria for the writing test}

Students' answer was counted based on the subsequent scoring criteria, as illustrated in the table below:

Table 3: scoring criteria to see the acquisition of -ing form structure (difficulties)

\begin{tabular}{|l|l|}
\hline \multicolumn{1}{|c|}{ Scoring } & \multicolumn{1}{c|}{ Criteria } \\
\hline 1 point & correct use of -ing form construction, understandable meaning \\
\hline 0 point & Incorrect use of - ing form construction, unclear meaning \\
\hline
\end{tabular}

The scoring was based on the total test items or possible constructions, 18 of 5 different word of -ing form. Each semester comprised 10 students. Therefore, if the group of the certain semester made all correct composition, the scoring would be 36 points because each student must have got only one word.

\subsection{Data Collection}

Data were provided from students' composition. The data were elicited by making use of free writing test by designing directions which could create -ing form productions in order to acquire the required data. All data were then grouped into two categories (the correct production and the deviant ones). Moreover, establishing interview was as well beneficial for additional interpretation of students' acquisition factors.

\subsection{Data Analysis}

To analyze the data, the researcher attempted to first encode students' composition-by comparing to other languages (translational technique) and substituted among sentence constituents (immediate constituents) proposed by (Sudaryanto, 2015). The following step was carried out by scoring the total correct answers in order to answer the first and second research questions. In addition, to acquire comprehensive understanding of particular phenomenon (students' misconception), the researcher tried to descriptively analyse and interpret students' misconceptions in the acquisition of -ing form structure based on the recording of interview on the tape.

\section{FINDINGS}

\subsection{THE LIST OF DATA FOR STUDENTS' SCORES AMONG THE GROUP OF SEMSETER}

To reveal the first research question, the researcher attempts to provide the required data to get more comprehensive explanation in relation to the role of frequency on students' accuracy or the development of students' linguistic representation among the groups that are illustrated in the subsequent table: 
Table 4: Students' score of correct answers

\begin{tabular}{|c|c|c|c|c|c|}
\hline Sem. & $\begin{array}{c}\text { Total } \\
\text { participant }\end{array}$ & $\begin{array}{c}\text { Total correct } \\
\text { scores }\end{array}$ & Percentage & Mean & SD \\
\hline 1 & 10 & $9 / 36$ & $25 \%$ & 0,9 & 0,31 \\
\hline 3 & 10 & $23 / 36$ & $63,8 \%$ & 2,3 & 0,48 \\
\hline 5 & 10 & $30 / 36$ & $83,3 \%$ & 3,0 & 0,00 \\
\hline 7 & 10 & $32 / 36$ & $88,8 \%$ & 3,2 & 0,42 \\
\hline $\mathbf{4}$ & $\mathbf{4 0}$ & $\mathbf{9 4 / 1 4 4}$ & $\mathbf{6 5 , 2 \%}$ & $\mathbf{2 , 3 5}$ & $\mathbf{1 , 9 8}$ \\
\hline
\end{tabular}

As illustrated in the table 3 above, participants of the $7^{\text {th }}$ semester group got the highest score; 32 of 36 or $88,8 \%$, accompanied by participants of the $5^{\text {th }}$ semester group 30 of 36 or $83,3 \%$, participants of the $3^{\text {th }}$ semester group 23 of 36 or $63,8 \%$, and participants of the $3^{\text {th }}$ semester group with the lowest score 9 of 36 or $25 \%$. The scoring was taken from each group of semester. Each semester consisted of 10 participants and the student respectively got only one type of 5 different words. Four words (studying, building, painting, and trying) were previously directed to be constructed into four possible constructions that mean 4 words or participants were multiplied by 4 different possible constructions that made 16. Meanwhile, the word (interesting) was probably constructed into two possible constructions based on the direction given so that 2 were added to 16 that made 18.18 points was counted from 5 participants whereas each group consists of 10 participants. Thus, 18 was multiplied by 2 that made 36 points, respectively for the group.

\subsection{THE ILLUSTRATION OF STUDENTS' SCORES AMONG THE GROUPS OF SEMESTER}

The scores among the group of semester in the figure below will demonstrate a comprehensive description regarding the role of frequency on the achievement of students' proficiency. Thus, the illustration of the figure can confirm the first research question which is illustrated in the subsequent figure:

Figure 1: Students' score of correct answers

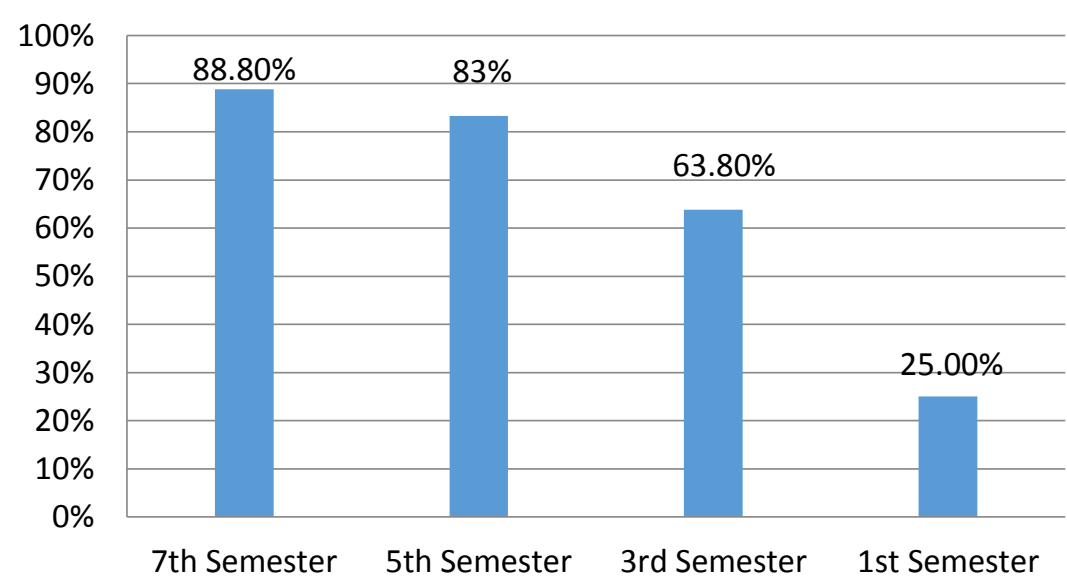

STUDENTS' SCORE OF CORRECT ANSWERS 
In addition, figure 1 illustrates a comprehensive explanation which describes that the higher semester of academic year students run, the higher score students got. It is otherwise that the lower semester of academic year students run, the lower score students got. The figure includes scales from 0 up to 100 percents that may be compared to students' achievement or accuracy of composing a sentence mainly containing -ing form. Even though the group respectively described various results, the total correct answers were generally derived from the highest rate of frequency which was frequently occurred as nominal, predicative, and adjectival as illustrated in table 4.

\subsection{THE LIST OF DATA FOR STUDENTS' PREFERENCE IN COMPOSING -ING FORM}

The count of students' preference is only derived from students' correct scores among the words. The rate of frequency on BNC corpus will be compared to students' preference to realize the role of frequency on students' constructional schemas. The list of data is provided in the subsequent table:

Table 5: Frequency effect on students' constructional schemas in the acquisition of ing form structure

\begin{tabular}{|c|c|c|c|c|c|c|c|c|c|c|}
\hline No & Word & \multirow[t]{3}{*}{ Function } & \multirow{2}{*}{\multicolumn{2}{|c|}{$\begin{array}{l}\text { Corpus } \\
\text { Frequency } \\
\quad(\text { BNC) }\end{array}$}} & \multirow{2}{*}{\multicolumn{4}{|c|}{$\begin{array}{c}\begin{array}{c}\text { Students' preference } \\
\text { of -ing form } \\
\text { construction }\end{array} \\
\text { Semester } \\
\end{array}$}} & \multirow{3}{*}{$\begin{array}{l}\text { Total } \\
\text { score }\end{array}$} & \multirow[t]{3}{*}{$\%$} \\
\hline \multirow{6}{*}{1} & \multirow{6}{*}{ Studying } & & & & & & & & & \\
\hline & & & Frq & $\%$ & 1 & 3 & 5 & 7 & & \\
\hline & & Nominal & $69 / 200$ & $34,5 \%$ & 1 & 2 & 3 & 3 & $9 / 32$ & $28,1 \%$ \\
\hline & & Predicative & $80 / 200$ & $40 \%$ & 1 & 3 & 2 & 3 & $9 / 32$ & $28,1 \%$ \\
\hline & & Adverbial & $4 / 200$ & $2 \%$ & - & - & - & 1 & $1 / 32$ & $3,1 \%$ \\
\hline & & Adjectival & $24 / 200$ & $12 \%$ & - & 1 & 2 & 1 & $4 / 32$ & $12,5 \%$ \\
\hline \multirow{4}{*}{2} & \multirow{4}{*}{ Building } & Nominal & $1116 / 200$ & $58 \%$ & 2 & 3 & 4 & 4 & $13 / 32$ & $40,6 \%$ \\
\hline & & Predicative & $2 / 200$ & $1 \%$ & - & 1 & 1 & 2 & $4 / 32$ & $12,5 \%$ \\
\hline & & Adverbial & $7 / 200$ & $3,5 \%$ & - & - & - & - & - & - \\
\hline & & Adjectival & $4 / 200$ & $2 \%$ & - & - & 1 & 1 & $2 / 32$ & $6,2 \%$ \\
\hline \multirow{4}{*}{3} & \multirow{4}{*}{ Painting } & Nominal & $141 / 200$ & $70,5 \%$ & 2 & 4 & 4 & 4 & $14 / 32$ & $43,7 \%$ \\
\hline & & Predicative & $6 / 200$ & $3 \%$ & - & 2 & 1 & 1 & $3 / 32$ & $9,3 \%$ \\
\hline & & Adverbial & $2 / 200$ & $1 \%$ & - & - & - & - & - & - \\
\hline & & Adjectival & $34 / 200$ & $17 \%$ & - & - & 2 & 1 & $4 / 32$ & $12,5 \%$ \\
\hline \multirow{4}{*}{4} & \multirow{4}{*}{ Interesting } & Nominal & 0/200 & 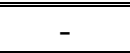 & 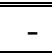 & 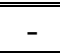 & - & 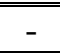 & - & - \\
\hline & & Predicative & $0 / 200$ & - & - & - & - & - & - & - \\
\hline & & Adverbial & $1 / 200$ & $0,5 \%$ & - & - & - & - & - & - \\
\hline & & Adjectival & $198 / 200$ & $99 \%$ & 1 & 2 & 3 & 4 & $10 / 16$ & $62,5 \%$ \\
\hline \multirow{4}{*}{5} & \multirow{4}{*}{ Trying } & Nominal & $52 / 200$ & $26 \%$ & - & 1 & 2 & 2 & $5 / 32$ & $15,6 \%$ \\
\hline & & Predicative & $93 / 200$ & 46,5 & 2 & 3 & 4 & 3 & $12 / 32$ & $37,5 \%$ \\
\hline & & Adverbial & $15 / 200$ & $7,5 \%$ & - & - & - & 1 & $1 / 32$ & $3,1 \%$ \\
\hline & & Adjectival & $25 / 200$ & $12,5 \%$ & - & 1 & 1 & 1 & $3 / 32$ & $9,3 \%$ \\
\hline \multicolumn{5}{|c|}{ Total } & 9 & 23 & 30 & 32 & $94 / 144$ & $65,2 \%$ \\
\hline
\end{tabular}


The scoring was carried out based on the total correct answer students prefer composing -ing form in the distribution of sentence constituents. The total possibilities are 94 compositions which consist of various distributions. The scoring is not only determined based on the constituent of sentences students composed but as well the reason students revealed during the interview. The scoring includes all groups of semester.

Data in the table 4 revealed that high frequency inputs of -ing form structure quoted from BNC corpus is fairly equivalent to students' preference in composing a sentence, nonetheless some others showed different results or no relation. The word 'studying' was constructed 6 of 32 or $28,1 \%$ as nominal, 6 of 32 or $28,1 \%$ as predicative, 1 of 32 or $3,1 \%$ as adverbial, 4 of 32 or $12,5 \%$ as adjective. The word 'building' was constructed 13 of 32 or $40,6 \%$ as nominal, 4 of 32 or $12,5 \%$ as predicative, 0 of 32 or $0 \%$ as adverbial, and 2 of 32 or $6,2 \%$ as adjective. The word 'painting' was constructed 14 of 32 or $43,7 \%$ as nominal, 3 of 32 or 9,3\% as predicative, 0 of 32 or $0 \%$ as adverbial, and 4 of 32 or $12,5 \%$ as adjectival. The word 'trying' was constructed 5 of 32 or $15,6 \%$ as nominal, 12 of 32 or $37,5 \%$ as predicative, 1 of 32 or 3,1\% as adverbial, and 3 of 32 or $9,3 \%$ as adjective. The word 'interesting' was constructed 0 of 16 or $0 \%$ as nominal, 0 of 16 or $0 \%$ as predicative, 0 of 16 or $0 \%$ as adverbial, and 10 of 16 or $62,5 \%$ as adjective.

\subsection{THE ILLUSTRATION OF STUDENTS' PREFERENCE IN COMPOSING -ING FORM}

Students' preference in composing -ing form will be described further in the figure below. The figure demonstrated the distribution of sentence constituents students prefer to make among the words. The illustration will be demonstrated at details in the subsequent table:

Figure 1:-students' preference of -ing form construction

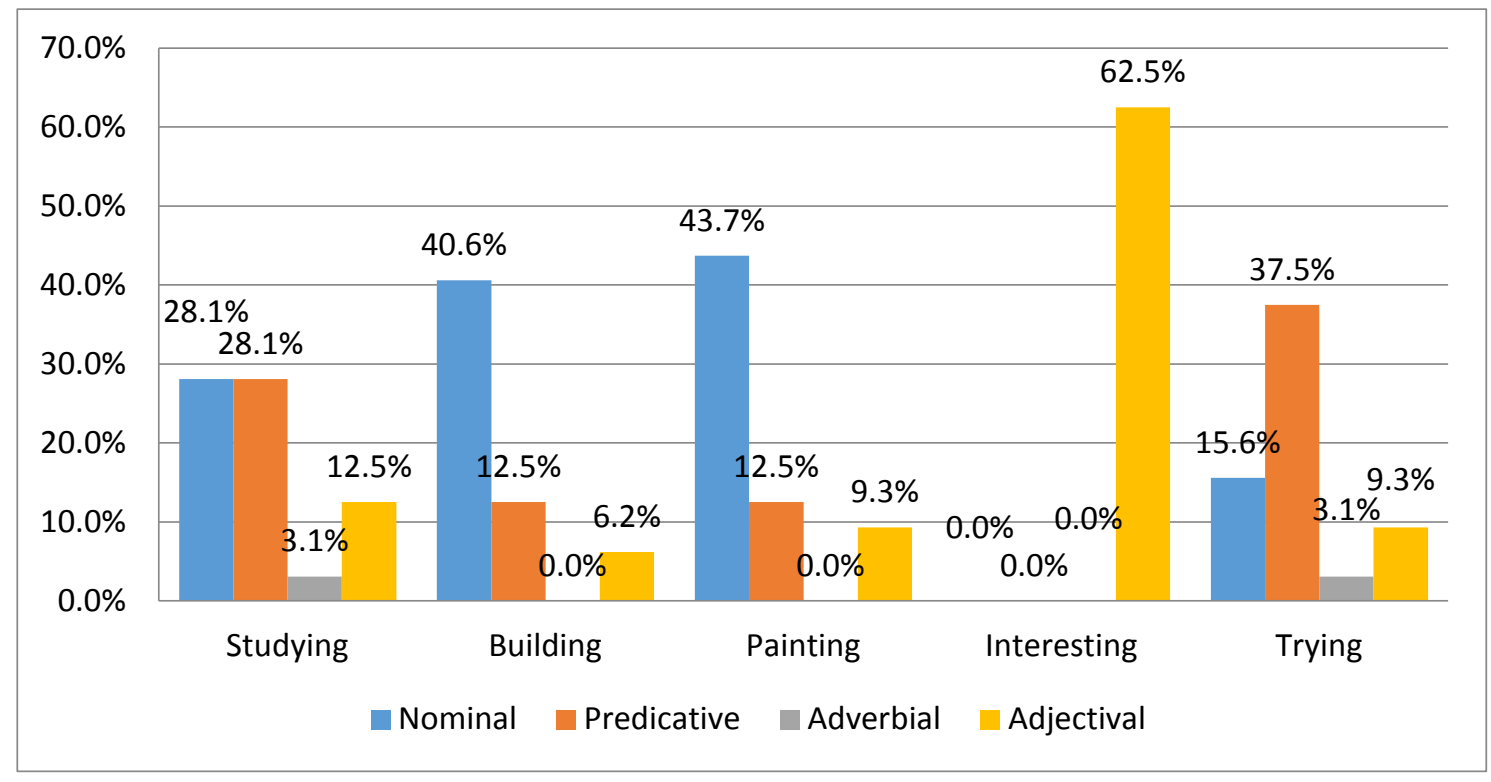


Figure 1 explains the relation of both frequency and students' preference more comprehensive. There are four different colours in relation to students' preference in determining their choices of -ing form constituents (nominal is implied by blue colour, predicative by red colour, adverbial by green colour, and adjectival by purple). The word "studying" is most frequently occurred as predicative quoted from BNC corpus 80 of 200 or $40 \%$. The results shows different in which nominal and predicative got the same scores $28,1 \%$, nonetheless the predicative constituents are frequently composed by them as well. The word "building" is most frequently occurred as nominal quoted from BNC corpus 116 of 200 or $58 \%$ and it is equivalent to students' preference in which the nominal constituents are frequently composed by them $40,6 \%$. The word "painting" is most frequently occurred as nominal quoted from BNC corpus 141 of 200 or $70,5 \%$ and it is equivalent to students' preference in which the nominal constituents are frequently composed by them $43,7 \%$. The word "interesting" is most frequently occurred as adjectival quoted from BNC corpus 198 of 200 or $98 \%$ and it is equivalent to students' preference in which the adjectival constituents are frequently composed by them 62,5\%. The word "trying" is most frequently occurred as predicative quoted from BNC corpus 93 of 200 or 46,5\% and it is equivalent to students' preference in which the predicative constituents are frequently composed by them $37,5 \%$.

\subsection{COMMON DEVIANT CONSTRUCTIONS}

The number of erroneous compositions is not as many as the correct ones. It occurs because the majority of word constructions are frequently exposed to students in advance. However, some are incorrect. It occurred because the constructions are rarely exposed to students' actual usage, different cognitive capacity, the completeness of instruction that is potentially responsible for any deviant production of language. The following is the list of data for categories of students' deviant compositions:

Table 6: misconceptions perceived by learners based on error categories

\begin{tabular}{|c|l|c|c|}
\hline No & $\begin{array}{c}\text { Misconception } \\
\text { (intra-lingual errors) }\end{array}$ & Frequency & Mean \\
\hline 1 & Incomplete application of rules & $22 / 144$ & $15,27 \%$ \\
\hline 2 & Ignorance of rule restrictions & $11 / 144$ & $7,63 \%$ \\
\hline 4 & False concepts hypothesized & $17 / 144$ & $11,80 \%$ \\
\hline
\end{tabular}

The majority of deviation productions were identified as developmental errors-ignorance of rule restriction, incomplete application of rules and false concept hypothesized. The total correct answers were 94 of 144 that the rest of the deviant constructions were 50 of 144. Incomplete application of rules was found the highest of all, scores 22 of 144 or 15,27\%.. Ignorance of rule restriction was 11 of 144 or $7,63 \%$. False concepts hypothesized was 17 of 144 or $11,80 \%$. It confirmed that -ing form was inaccurately constructed yet. The deviant productions were affected by different strategies of English learning and a small number of prior usage inputs acquired based on the existing structure. Again, the frequency fairly contributes to strengthen students' constructional schemas or cognitive capacity. 


\section{DISCUSSION}

\subsection{Does the rate of frequency contribute to students' accuracy in composing - ing form structure?}

Based on the table 3 and figure 1, the result confirmed that -ing form structure as the linguistic knowledge of abstract representation could be probably easy to acquire not only dependent on how frequent the acquirers were exposed to particular language use input, but as well students' cognitive capacity, the completeness of instruction, different learning sources may contribute to the achievement of language learning (Brown, 1973; Brown, 2000). The findings revealed that each semester got distinct scores. The higher semester the participants run, the higher score they got. The higher semester probably indicated that the language exposure, the completeness of instruction, learning sources could be various among students.

According to the usage-based perspective proposed by a number of experts, the acquisition of abstract representation of linguistic feature or the linguistic knowledge is affected by the frequent language use (Baybee, 2010; Bybee \& Thompson, 1997; Croft \& Cruse, 2004). In addition, the repeated experiences of using certain linguistic features are also allowed to strengthen the constructional schemas of conceptual representation in mind (Dabrowska, 2004; Schwartz \& Causarano, 2007; (Langacker, 2008). Even though a large number of students could construct a sentence containing -ing form correctly, the construction was just restricted to the common forms they used to acquire in advance. The constructions of -ing form which were composed by students were dominantly distributed as nominal and predicative, adjectival because -ing form as predicative and nominal, and adjectival were less abstract or regarded as lower-level construction than those of adverbial constituents. However, it is dependent on the tendencies of its internal structure.

Therefore, the rate of frequency does not fairly influence students' accuracy in composing -ing form structure because of numerous reasons; Different cognitive capacity among students, the completeness of instruction, different learning sources.

\subsection{Does Frequency affect students' constructional schemas or preference in the acquisition of -ing form structure?}

Based on the table 4 and figure 1, the high frequency of -ing form construction found in BNC corpus corresponded with students' preference in composing a sentence and correction of students' composition. Therefore, the higher frequency of sentence distributions was nominal (painting and building), predicative (trying and studying), and adjectival (interesting) based on the rate of frequency inputs found in BNC corpus. The total count was equivalent to students' preference that is higher as well. Meanwhile, the distribution of adverbial constituents is lower than three constituents.

Repetitive experiences of using a word or the high frequency of a word which is exposed will strengthen the representation of a word in the acquirers' mind so that it is more easily activated by students to use later on (Dabrowska, 2004; Schwartz \& Causarano, 2007; (Langacker, 2008). The word 'painting' was more frequently accessed by learners as nominal so that the word 'painting' was also easily 
constructed by students as nominal. It could be actually confirmed in accordance with the total score of their answer and the students' preference in composing a sentence containing -ing form. The result suggested that the high frequency of -ing form occurring in the possible constructions contributed to students' preference in the acquisition of -ing forms. Last but not least, students' ability in constructing a sentence would be developed if students' cognitive capacity had also grown up. Besides, the previous linguistic inputs should be delivered carefully whether or not they are acceptable in accordance with the internal linguistic system of target language so that students can avoid the fossilization of error productions (Maigoro et al., 2017)

\subsection{What kinds of misconception perceived by Indonesia $L 2$ learners in the acquisition of -ing form construction?}

\subsubsection{Incomplete Aplication of Rules}

This category of error is typically caused when a language learner does not apply appropriate structure of the target language (Richards, 1974). As illustrated in the table 5 above, intra-lingual error includes incomplete application of rules which are perceived by learners in constructing -ing form by omitting or adding elements of particular linguistic features. The example of the category in composing -ing form was found like;

[1] Rani always painting fruit on the white board.

[2] The student trying to learn English.

The student thought that [1] 'painting' could be applied to refer to the regularity. The -ing form was occasionally neutral to every aspect and enabled the indication of regularity (Quirk., et. al, 1985). 'always', for example, John takes a seat under the tree, always listening to music. However, another matrix clause should take a role to indicate the regularity - which was equivalent to its dependent clause. In this case, the sentence was constructed as simple and there was no matrix clause indicating the regularity. The construction was preferred to be 'Rani always paints fruits on the white board'

The student thought that [2] the sentence constituted a progressive aspect. The student considered that the sentence was equivalent to affirmative present form which was unnecessarily put any auxiliary. If it was so, the construction would be more likely a modification than that of the main verb. The -ing form can act as modification (object complement, subject complement, noun phrase modifier) (Quirk., et. al, 1985). The construction was preferred to be 'the student is trying to learn English.'

\subsubsection{Ignorance of rule restriction}

This category is still regarded as generalization but what is significantly distinct is that the student does not manage to observe any restriction of particular rules. Moreover, the category of error typically occurs in certain cases (Richards, 1974). As illustrated in the table 5, this category of error was found in students' composition, for example:

[1] Any loves to painting the nature 
[2] My little brother wants painting in the wall.

The Sentence [1] was not totally wrong yet it was grammatically ambiguous that probably affected the meaning. -ing form could act as prepositional object (Quirk., et.al, 1985). This reason led students to misconception. The particle 'to'probably acts for the infinitive constituent or preposition (Greenbaum \& Nelson, 2002). Based on students' opinion, they confirmed that the construction was considered explaining Any's excitement of painting the nature that directly involved Any as the doer performing herself in the action instead of another doer's action. Moreover, the verb love includes a transitive which unnecessarily put any prepositional item. The construction was preferred to be 'Any loves painting the nature.'

The sentence [2] was another misconception perceived that ignored particular structure. Verbs could take -ing form or infinitives as verbal complements (Quirk., et.al, 1985). Conversely, the verb 'want' typically took infinitive other than -ing form. If 'want' then took -ing form, the -ing form would be perceived as passive (see dict. 'want'). Additionally, the student gave opinion that 'painting' was an action 'my little brother' performed other than a product of action that was equivalent in meaning to 'picture' (Quirk., et.al, 1985). The construction was preferred to be 'my little brother wants to paint on the wall'

\subsubsection{False concepts hypothesized}

This category constitutes a developmental error which has to do with the faulty conception of distinction in the target language (Richards, 1974). The deviation was also found in the subsequent instance;

[1] I was interesting with the new model of those brand shoes.

[2] Painting is such a refreshing thing to do.

The sentence [1] was inaccurately perceived by students. They thought 'interesting' indicated someone's being attracted to something. However, in the sentence implied the performer's action in attracting others. The -ing construction was not accurately put in the construction so that $-e d$ form which was collocated with prep-'in' was found better. -ing form in this case so-called as -ing participle or -ing deverbal adjective was derivationally adjective and inflectionally subject complement in this occasion (Taher, 2015). The construction was preferred to be ' $\mathrm{i}$ was interested in the new model of those shoe brands.'

The sentence [2] was not totally wrong yet it was grammatically ambiguous. ing form can be named as verbal noun (-ing deverbal noun) which is lexically noun and inflectionally nominal or as nominal verb (gerundive) which is lexically verb and inflectionally nominal (Taher, 2015). When -ing form is modified by adjective or determiner, the construction will be verbal noun. Conversely, when -ing form is modified by object or adverb, it will be nominal verb (gerundive) (Quirk., et.al, 1985). Moreover, -ing form is avoided when occurs alone or genitive case (Quirk., et.al, 1985). In this case, the student though that 'painting' was the action other than the product of action (picture). Thus, this construction was complicated to understand by students. If it was so, 'painting' was preferred to put another object or 
adverbial in order to be what was denoted as the action itself. The construction was preferred to be 'painting the scenery is such a refreshing thing to do'.

\section{CONCLUSION}

The result revealed that the frequency could affect students' constructional schemas in the acquisition of -ing form. It was also dependent on each student's cognitive capacity. The higher frequency of -ing form structure was widely accessed, the easier the students could compose a sentence. Therefore, the reasons of deviant production were caused by a small number of language input concerning ing form structures acquired by learners, low intensity of practice, and different cognitive capacity. The limitations of the study comprised [1] the participants are not many, [2] further studies should contain a higher number of verb types not only 5, [3] the searching of corpus' data that denote the possible constructions should be multiplied by 500 or 100 and the utilization of some other corpora would enhance the comprehensibility of -ing form structure. Hopefully, the findings of the research may assist instructors design materials and plan essential learning and teaching strategies. Routine practices should be given to students to acquire inputs and the foundation of constructional schemas. It can be conducted by sending students reading texts, English portal news, English conversation audio and so forth. Last but not least, sending explicit knowledge as a feedback should be considered in order to avoid any fossilization of deviant production.

\section{REFERENCES}

Baybee, J. (2010). Language, usage and cognition (1st ed.). Cambridge University Press.

Brown, H. D. (2000). Principles of language learning and teaching. White Plains, New York: Longman Group Limited.

Brown, R. (1973). A first language: The early stages. London: George Allen \& Unwin.

Bybee, J., Thompson, S. (1997). Three frequency effects in syntax. In Proceedings of the Twenty-Third Annual-Meeting of the Berkeley-inguistics Society ( $\mathrm{p}$. 378-388.).

Croft, W., Cruse, A. D. (2004). Cognitive linguistics. Cambridge University Press.

Dabrowska, E. (2004). Language, mind and-brain: Some-psychological and neurological constraints on theories of grammar. Washington, D.C.: Georgetown University Press.

Ellis, N. (2002). Frequency-effects in language processing: A review withimplications for theories of implicit and explicit langauge acquisition. SSLA, 24, 143-188. https://doi.org/10.1017.S0272263102002024

Greenbaum, S., \& Nelson, G. (2002). An introduction to English grammar. United Kingdom: person education limited.

Keawchaum, R., \& Pongpairoj, N. (2017). The Role of Frequency on the Acquisition of L2 English Infinitive and Gerund Complements by L1 Thai Learners. PASAA: Journal of Language Teaching and Learning in Thailand, 
$54,29-57$.

Kitikanan, P. (2011). Thai EFL Students' Ability to use the Gerund and Toinfinitive. International Journal of the Humanities, 9 No 2, 279-290. https://doi.org/10.18848/1447- 9508/CGP/v09i02/43131

Krashen, S. D. (1981). Second Language Acquisition and Second Language Learning. Oxford: Pergamon. https://doi.org/10.1787/9789264230750-en

Langacker, R. W. (2008). Cognitive-grammar: A basic introduction. New York: Oxford University Press.

Maigoro, I. L., Nansoh, M. D., Williams, Ezekiel Dazi Pam., \& Manji, M. (2017). The Relationship Between Types of Misconceptions and Achievement In Genetics Among Senior Secondary School Biology Students In Jos North Lga of Plateau State. European Centre for Research Training and Development, $3(5), 1-26$.

Norrish, J. (1983). Language Learners and Their Errors. Macmillan Education.

Quirk, R., Greenbaum, S., Leech, G., \& Svartvik, J. (1985). A Comprehensive Grammar of The English Language. Longman Group Limited.

Richards, J. C. (1974). Error Analysis. Longman Group Limited.

Schwartz, M., \& Causarano, P. L. (2007). The role of-frequency in SLA: An analysis-of gerunds and infinitives in ESL written discourse. Arizona-Working Papers in SLA \& Teaching, 14, 43-57.

Sudaryanto. (2015). Metode dan Aneka Tehnik Analisis Bahasa. Yogyakarta: Duta Wacana University Press.

Taher, I. I. (2015). The Problematic Forms of Nominalization in English: Gerund, Verbal Noun, and Deverbal Noun. English Linguistics Research, 4(1), 30-40. https://doi.org/10.5430/elr.v4n1p30

Tomasello, M. (2003). Constructing a language: A usage-based theory of language acquisition. Harvard University Press.

Vercellotti, M. L., \& De Jong, N. (2013). Use and accuracy of verb complements in English L2 speech. Dutch Journal of Applied Linguistics, 2(2), 243-250. https://doi.org/10.1075/dujal.2.2.05lou 